\title{
Cancer in Canada in 2008
}

\author{
Loraine D. Marrett PhD, Prithwish De MHSc PhD, Parisa Airia MD MSc, Dagny Dryer MD, \\ for the steering committee of Canadian Cancer Statistics 2008
}

I $\mathrm{n}$ this article, we describe the changing size and nature of the cancer burden in Canada by reviewing the major findings from the 2008 edition of Canadian Cancer Statistics, which has been published annually since 1987 . We also examine Canadian cancer statistics in the context of international cancer trends.

There were an estimated 12 million new cases of cancer worldwide in 2007. Of these, 5.4 million cases occurred in developed countries and 6.7 million occurred in developing countries. ${ }^{1}$ By 2050, the annual global burden of cancer will reach 27 million new cases and 17.5 million cancer deaths. In Canada, it is estimated that 166400 people will receive a diagnosis of cancer in 2008, and 73800 will die from the disease (Table 1). ${ }^{2}$ An additional 73000 will receive a diagnosis of nonmelanoma skin cancer. ${ }^{2}$ These numbers will likely continue to increase each year because of a growing and aging population.

In Canada, cancer will develop in $45 \%$ of men and $39 \%$ of women during their lifetime, and about 1 in 4 Canadians will die of the disease. ${ }^{2}$ In 2004, about 850000 Canadians, or $2.7 \%$ of the Canadian population, had received a diagnosis of cancer at some time during the past 15 years. This number will also continue to increase because of the growing number of new cases and improvements in survival. These trends have important implications for health care planning and delivery because a greater awareness of past and present trends can help characterize the future burden as well as prioritize prevention and screening efforts.

\section{Development of Canadian Cancer Statistics 2008}

\section{Data sources}

The analytic methods have been described in detail. ${ }^{2}$ Data were drawn from 3 main sources. First, new cases of cancer were identified from the Canadian Cancer Registry (since 1992) and the National Cancer Incidence Reporting System (between 1969 and 1991). Second, deaths due to cancer were identified from the Canadian Mortality database. Third, population estimates were obtained from national censuses and forecasts prepared by Statistics Canada. Although provincial and territorial organizations collect information on new cancer cases and deaths, Statistics Canada is the national repository for the data.

Incidence data for new cases of cancer were available up to 2005 for most provinces and territories. Data were avail-

\section{Key points}

- Incidence rates for all cancers combined were stable during the past decade, but the number of new cancer cases continues to increase because of population growth and aging.

- Mortality rates are declining, both for all cancers combined and for many different types of cancer, because of improvements in early diagnosis and treatment.

- Rates are increasing significantly for a few types of cancer (e.g. incidence and mortality due to liver cancer in men, incidence of thyroid cancer in men and women, and mortality due to lung cancer in women).

- The number of living Canadians who have received a diagnosis of cancer at some time during the past 15 years continues to increase because of improved survival and the rising number of new cases.

- Current trends warrant appropriate prevention and health promotion programs, diagnosis, treatment, support and palliative care.

able up to 2004 for Quebec, Manitoba and Alberta. Mortality data were available for all provinces and territories to 2004. Data do not include in situ cancers, except for cases of in situ bladder cancer, which were reported from all provinces except Ontario.

\section{Analysis}

The numbers of new cases and deaths beyond the period for which data were available were estimated using Poisson regression modelling. Occasionally, estimates were based on 5-year averaging instead of modelling (e.g., where numbers were small or trends were irregular). Analyses of data from 1987 to 1991 have shown most estimates to be within $10 \%$ of actual data. ${ }^{3}$ The estimates are suspected to be less variable in recent years because of improved estimation methods.

We obtained the 15-year prevalence (i.e., the number of patients alive in 2004 who had received a diagnosis of cancer in the 15-year period between 1990 and 2004) by applying survival rates from the Saskatchewan Cancer Registry (national data were unavailable) to the Canadian cancer incidence data. Incidence and mortality rates by type of cancer, province and territory, sex, age group and year were calcu-

From Population Studies and Surveillance (Marrett), Cancer Care Ontario; Cancer Control Policy and Information (De), Canadian Cancer Society; the National Cancer Institute of Canada (De); the Dalla Lana School of Public Health (Airia), University of Toronto, Toronto, Ont.; and the PEI Cancer Treatment Centre (Dryer), Charlottetown, PEI 


\begin{tabular}{|c|c|}
\hline Observation & Estimate \\
\hline No. of new cases* & 166400 \\
\hline No. of deaths & 73800 \\
\hline \multicolumn{2}{|l|}{ Incidence rate, all cancer types* } \\
\hline Women & 361 per $100000 t$ \\
\hline Men & 462 per $100000 t$ \\
\hline \multicolumn{2}{|l|}{ Mortality rate, all cancer types } \\
\hline Women & 147 per $100000 t$ \\
\hline Men & 209 per $100000 t$ \\
\hline \multicolumn{2}{|l|}{ Most commonly diagnosed cancers* } \\
\hline Women & breast, lung, colorectal \\
\hline Men & prostate, lung, colorectal \\
\hline \multicolumn{2}{|l|}{ Leading causes of cancer death } \\
\hline Women & lung, breast, colorectal \\
\hline Men & lung, colorectal, prostate \\
\hline $\begin{array}{l}5 \text {-yr relative survival rate, all cancers* } \\
(2001-03), \% \text { (range) }\end{array}$ & $62(6-98)$ \\
\hline \multicolumn{2}{|l|}{ 15-yr prevalence in 2004 for all cancers } \\
\hline Women (\% of female population) & $456500(2.8)$ \\
\hline Men ( $\%$ of the male population) & $396900(2.5)$ \\
\hline
\end{tabular}

also being made to ensure systematic collection of data about the stage of cancer at diagnosis for newly diagnosed cases. ${ }^{5}$

A concern with the analysis of cancer mortality data, which come from death certificates, is that the absence of cancer as an antecedent cause may not ensure the absence of cancer. In addition, there is the potential for misclassification of the underlying cause of death. However, no studies are available to assess the extent of these limitations for mortality data in Canada.

There is a level of uncertainty about estimates for years beyond those covered by actual data. Cancers that have irregular trends, such as prostate cancer, present the greatest challenge to accurately estimate future numbers. The steering committee is currently evaluating alternate forecasting methods with a view to improve data presented in Canadian Cancer Statistics. ${ }^{2}$ It is reassuring, however, that there is general coherence of patterns and trends with similar jurisdictions, such as the United States, that use different methods of cancer registration. lated by dividing the number of new cases or deaths by the corresponding provincial or territorial population. Rates were directly age-standardized by 5-year age groups to the 1991 Canadian population. We assessed trends over time by estimating the average annual percentage change. Statistically significant changes were identified by change-point analysis. We used the period method to estimate the 5-year relative survival ratios between 2001 and 2003. These ratios are reported as percentages and were calculated as the ratio of the observed survival for a group of patients with cancer to the survival expected for people of the same age, sex, province or territory, and time period in a cancer-free general population.

\section{Limitations of surveillance data}

The data sources and methods for cancer registration as well as timeliness, completeness and accuracy of data used for deriving the estimates vary across jurisdictions. For example, registries in Newfoundland and Labrador and Quebec were each missing a data source considered to be important for high-quality cancer registration. Registries in Newfoundland and Labrador do not include information from death certificates, and those in Quebec do not include all pathology reports. As a result, the incidence rates of cancer in these provinces are likely underestimated, particularly for types of cancer that rely more heavily on these data sources, such as melanoma diagnoses in Quebec. ${ }^{4}$ The Canadian Council of Cancer Registries is currently developing a framework to enhance data quality. Efforts are

\section{Prevalence, incidence, mortality and survival}

About 166400 Canadians (79 400 women and 87000 men) are expected to receive a diagnosis of cancer in 2008 . About 35000 women and 38800 men are expected to die of cancer in 2008 (Table 2). This is an increase of 6500 new cases and 1100 deaths over 2007. Despite the higher number of cases and deaths among men, there is a higher incidence of cancer among women aged 20-59 years. The mortality rates among women in their 30 s and 40 s are higher than among men of a comparable age.

The prevalence of cancer is also increasing because of the increasing number of new cases each year as well as improved survival. Thus, it is imperative that we better understand the issues faced by cancer survivors. In 2004, there were 850000 living Canadians who had received a diagnosis of cancer at some time in the previous 15-year period (2.5\% of men, $2.8 \%$ of women). Breast cancer is the most prevalent cancer among Canadian women. In 2004, there were 166000 women (1.0\% of women) who had received a past diagnosis of breast cancer. Among men, prostate cancer is the most prevalent cancer, with about 127200 men ( $0.8 \%$ of men) having received a cancer diagnosis in the past 15 years.

In general, cancer incidence and mortality rates were highest in Atlantic Canada and Quebec and were lowest in British Columbia in 2008. This pattern is consistent with previous years. Regional differences may be because of variation in the prevalence of cancer risk factors (e.g., smoking rates have 
been historically higher in Quebec and Atlantic Canada ${ }^{6}$ ) or because of variation in the early detection of cancer because of differing levels of participation in screening activities or differences in availability of diagnostic services. These differences may also be because of variation in access to and quality of treatment, variation in population risk because of different ethnic backgrounds, or data quality issues related to surveillance. Lung and colorectal cancer account for most of the observed regional variation. Although lung cancer is likely related to differences in exposure to tobacco smoke (first and second-hand), the explanation for colorectal cancer is less clear. It may be partly related to differences in diet, physical activity and obesity.

The 5-year relative survival ratio was $62 \%$ for all cancers combined from 2001 to 2003. Thyroid cancer had the highest estimated 5-year relative survival ratio, and pancreatic cancer

Table 2: Estimated number of new cancer cases and deaths for selected cancers in Canada in $2008^{2}$

\begin{tabular}{|c|c|c|c|c|}
\hline \multirow[b]{2}{*}{ Type } & \multicolumn{2}{|c|}{ No. of new cases } & \multicolumn{2}{|c|}{ No. of deaths } \\
\hline & Men & Women & Men & Women \\
\hline Prostate & 24700 & - & 4300 & - \\
\hline Breast & NR & 22400 & NR & 5300 \\
\hline Bladder & 5100 & 1700 & 1250 & 530 \\
\hline Body of the uterus & - & 4200 & - & 790 \\
\hline Non-Hodgkin lymphoma & 3800 & 3200 & 1700 & 1400 \\
\hline Kidney & 2700 & 1750 & 1000 & 600 \\
\hline Brain & 1450 & 1100 & 1000 & 740 \\
\hline Oral & 2300 & 1100 & 760 & 380 \\
\hline Pancreas & 1800 & 1950 & 1800 & 1950 \\
\hline Esophagus & 1200 & 410 & 1300 & 430 \\
\hline Ovary & - & 2500 & - & 1700 \\
\hline
\end{tabular}

Note: NR = not reported.

Table 3: Average annual percentage change in age-standardized incidence and mortality rates of cancers in Canada, 1995-2004

\begin{tabular}{|c|c|c|c|c|}
\hline \multirow[b]{2}{*}{ Type } & \multicolumn{2}{|c|}{$\begin{array}{c}\text { Incidence; * } \\
\text { average annual percentage change }\end{array}$} & \multicolumn{2}{|c|}{$\begin{array}{c}\text { Mortality;* } \\
\text { average annual percentage change }\end{array}$} \\
\hline & Men & Women & Men & Women \\
\hline Lung & -2.5 & - & -2.1 & - \\
\hline Stomach & -2.3 & -2.4 & -3.6 & -3.1 \\
\hline Brain & - & -3.6 & - & - \\
\hline Prostate & - & - & -2.9 & - \\
\hline Hodgkin lymphoma & - & - & -4.2 & -3.7 \\
\hline Non-Hodgkin lymphoma & - & - & -2.3 & - \\
\hline Oral & - & - & -2.5 & - \\
\hline Larynx & -3.6 & -3.4 & -3.2 & - \\
\hline
\end{tabular}

*Only data for cancers with at least a $2 \%$ statistically significant change per year are reported. 


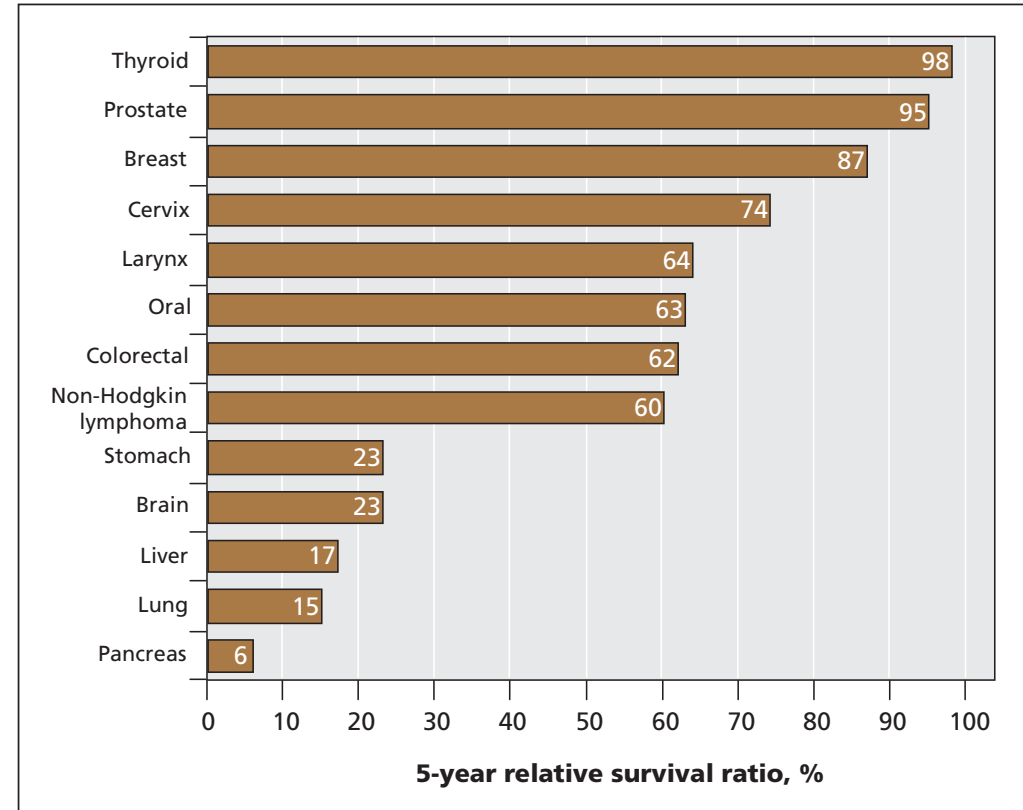

Figure 1: Estimated 5-year relative survival ratio for selected cancers in Canada (excluding Québec), 2001-2003. ${ }^{2}$

had the lowest (Figure 1). Relative survival ratios are generally lowest in the oldest age groups (patients aged $\geq 80$ year), but there are 2 exceptions. The youngest group of patients with breast cancer (aged 20-39 years) or prostate cancer (aged 40-49 years) had lower relative survival ratios compared with older age groups (except for those aged 80-99 years) (Figure 2). Rela- tive survival for lung cancer is significantly lower than for other major cancers, and survival decreases with increasing age.

\section{Trends in major cancers}

In general, the incidence rate has been stable for all cancers combined since 1979 . However, the rates are increasing for some types of cancer and decreasing for others. In contrast, the mortality rate is decreasing for all cancers combined and for most specific types of cancer. Annual percentage changes for selected cancers are shown in Table 3.

\section{Breast cancer}

The incidence of breast cancer rose steadily between 1979 and 1999 but has since declined by $1.7 \%$ per year (Figure 3). Much of the increase was likely because of increased uptake of screening mammography during the 1980s and 1990s. Screening may have eventually exhausted the pool of prevalent cancers in the screened population, resulting in the more recent decline as the incidence rate decreased to prescreening levels. Changes in risk and protective factors, such as changing patterns of childbearing and hormone use, may have also influenced this trend.

The mortality rate for breast cancer has fallen by more than 25\% since 1986 (Figure 4). This is likely the result of a combination of uptake of mammography screening, and the use of more effective adjuvant therapies after breast cancer surgery.

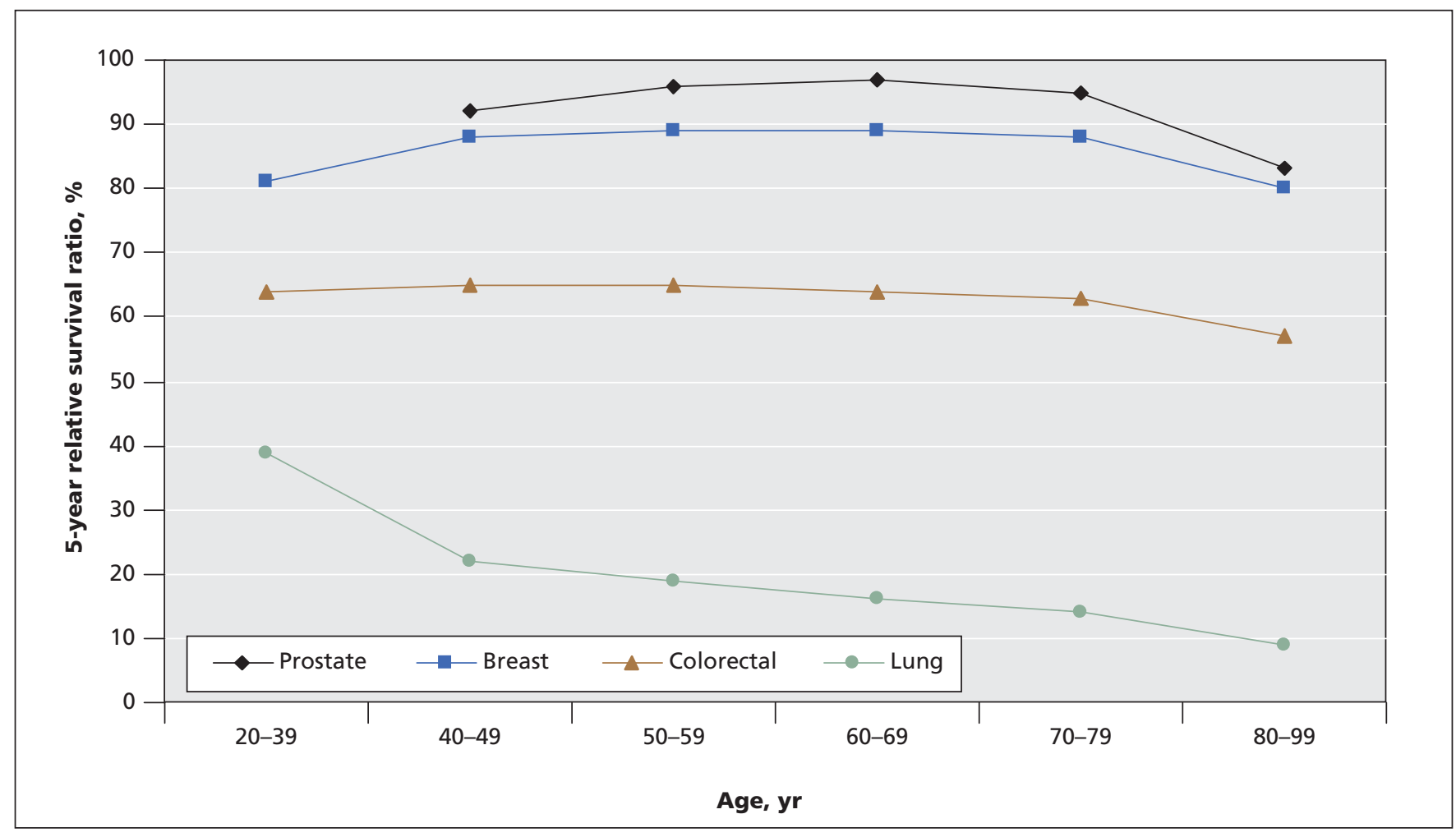

Figure 2: Estimated 5-year relative survival ratios for major cancers in Canada (excluding Québec), by age at diagnosis, 2001-2003. ${ }^{2}$ 


\section{Prostate cancer}

The incidence rate of prostate cancer continues to increase moderately (Figure 3). The peak incidence rates in 1993 and 2001 are compatible with 2 waves of intensified screening activity with the prostate-specific antigen (PSA) test for early detection of prostate cancer. The first wave in 1993 followed the introduction of PSA as a screening test. The second wave in 2001 may be explained by the publicity around the then minister of health's diagnosis of prostate cancer as a result of serial PSA tests.

In contrast, mortality rates rose much more slowly after 1979 (Figure 4). Since the mid-1990s, rates have declined by $2.9 \%$ per year, likely because of a combination of earlier detection and improved treatment.

\section{Colorectal cancer}

The incidence rate of colorectal cancer, particularly among women, has fluctuated since 1979 . It has recently begun to decline (Figure 3).

The mortality rate has been falling among both men and women over the past 2 decades (Figure 4), likely as a result of improvements in chemotherapy. Screening for colorectal cancer can reduce both the incidence and mortality. Limited screening activity has already been occurring in some provinces, which may account for some of the decline in mortality. Several provinces have announced that they are implementing population-based screening programs for colorectal cancer. Other provinces are reviewing similar proposals.

\section{Lung cancer}

Among men, the incidence and mortality rates began to decline in the mid-1980s (Figure 3). Among women, incidence and mortality rates have been increasing since at least 1979, and continue to do so (each by $1.2 \%$ per year). However, the incidence continues to be higher among men (67 per 100000$)$ than among women (51 per 100 000). The mortality is also higher among men (59 per 100 000) than among women (40 per 100 000). These patterns reflect the decrease in tobacco consumption that began in the mid-1960s for men and mid-1980s for women. ${ }^{6}$

\section{Survival}

The 5-year relative survival has been improving over time. The current relative survival ratio for all cancers is $62 \%$. This figure is driven in part by the poor to fair survival for lung and colorectal cancer, 2 of the most common types of cancer. The decreasing incidence rate of lung cancer in men, which is a reflection of past declines in smoking prevalence, will ultimately lead to improved overall survival because of proportionally fewer cases of lung cancer. Improved overall survival will occur sooner for men than for women, because the impact of lower smoking rates on the incidence of lung cancer in women will take longer to become apparent. For colorectal cancer, implementation of screening programs in many provinces is expected to improve survival.

\section{Trends in emerging cancers}

The age-standardized incidence rates of several cancers changed significantly between 1995 and 2004. Those with an average
A

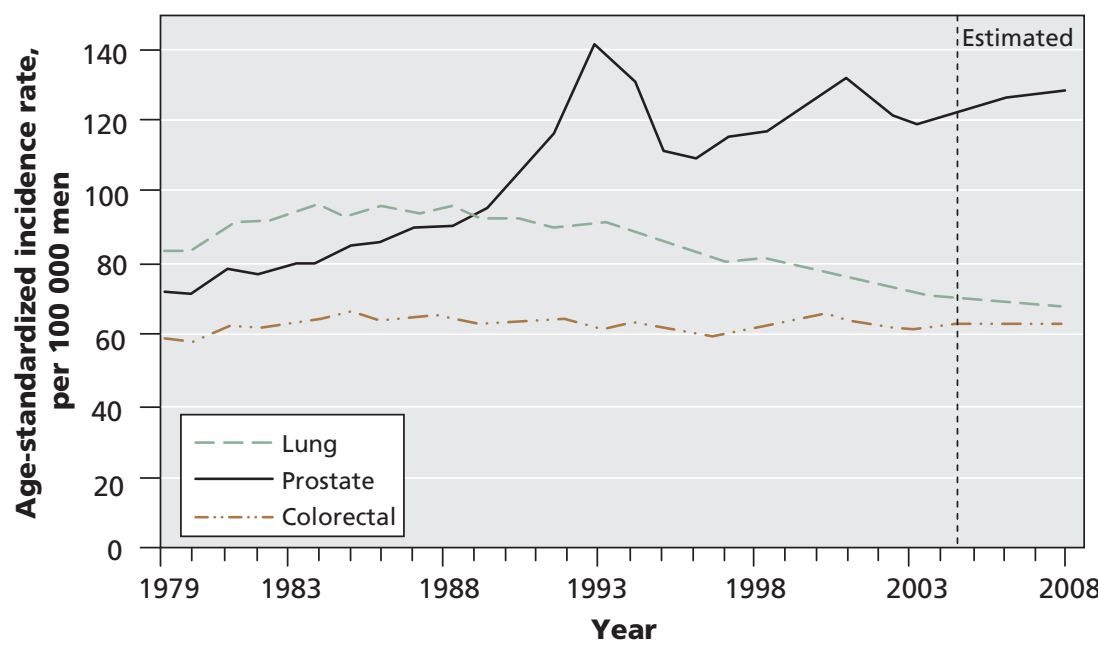

B

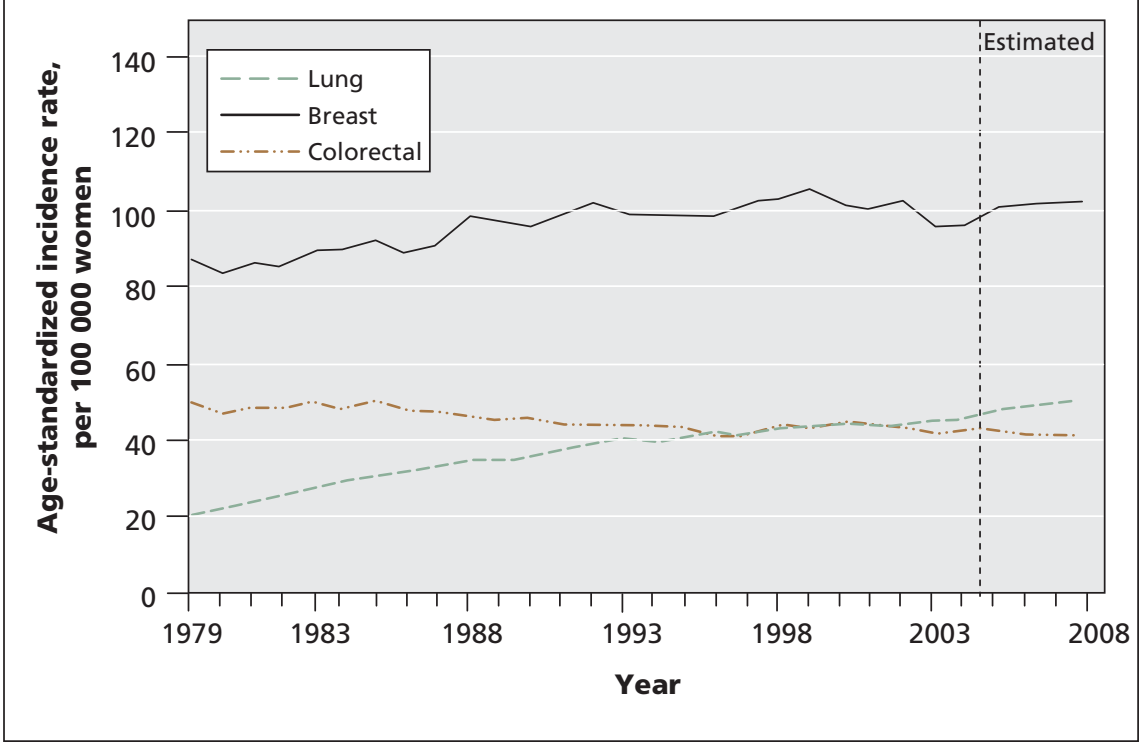

Figure 3: Trends in age-standardized incidence rates for major cancers for men (A) and women (B) in Canada, 1979-2008. ${ }^{2}$ The numbers of new cases and deaths beyond the period for which data were available were estimated using Poisson regression modelling. 
annual percentage change of $2 \%$ or more are shown in Table 2. Many of the downward trends in incidence rates (and corresponding declines in mortality) are continuations of the longterm trends and relate predominantly to changes in risk factors or screening. The only cancers with strong and significantly increasing incidence rates are thyroid and liver cancer. The incidence rate of thyroid cancer has risen dramatically in both sexes, as have the incidence and mortality rates of liver cancer in men.

The change in the incidence rate of thyroid cancer is probably largely because of enhanced detection of small or indolent cancers. ${ }^{8}$ The mortality rate for thyroid cancer is very low and stable. Survival after thyroid cancer is excellent, most likely because modern treatments are highly effective in the management of thyroid cancers when detected early. Thyroid cancer is one of the few cancers that occurs more frequently in women than in men (ratio of nearly 4:1). It is also one of the most common cancers in young women, ranking second after breast cancer in women aged 20-49 years. Increasing numbers of young women are therefore receiving a diagnosis of and treatment for this cancer and are likely to live for a long time as cancer survivors. Survivorship issues are therefore important to consider as the incidence of cancer rises in young adults, particularly among women aged 20-39 years and men aged 20-29 years.

In contrast, the relatively low but increasing rates of liver cancer incidence and mortality, particularly among men, are likely related to the prevalence of hepatitis $\mathrm{B}$ and $\mathrm{C}$ infections. This may, in part, be because of changing patterns of immigration, whereby an increasing proportion of the population was born in countries where hepatitis B is endemic or where exposure to liver toxins, such as aflatoxin, are common. ${ }^{9}$ In Europe and the United States, it is estimated that about $22 \%$ of primary liver cancers are attributable to hepatitis B infection, $60 \%$ to hepatitis $\mathrm{C}$ infection, and $57 \%$ to alcoholrelated cirrhosis and obesity. ${ }^{10}$

\section{International comparisons}

Incidence rates for cancer in Canada are comparable to rates in other developed countries, such as the United States, Australia and the United Kingdom. However, incidence rates in Canada are much higher than those in less developed regions (Table 4). Incidence rates are nearly twice as high in the developed world compared with less developed regions. ${ }^{1,11,12}$ Incidence rates of the most commonly diagnosed cancers (lung, colon, breast, prostate) and mortality rates for leading causes of cancer are generally similar across developed countries. ${ }^{11,12}$ Similar overall trends and patterns are also seen in other developed countries for many cancers where historical trends in risk factors, such consumption of tobacco or uptake of screening, such as PSA testing among asymptomatic men, are comparable. ${ }^{13}$

The patterns of cancer are different in less developed nations, where infectionrelated cancers, such as stomach, liver and cervical cancer, are proportionally more common than in developed nations. ${ }^{11,12}$ The percentage of cancers due to infectious agents in developing coun- 
tries $(26 \%)$ is more than 3 times that in developed countries $(8 \%) .{ }^{14}$ However, the distribution of cancer types has been changing in both developed and developing nations as a result of migration and a shift in the burden of infectious diseases to ailments related to Western lifestyles, respectively. ${ }^{12}$

Many cancer registries outside Canada are not populationbased. Some may cover only urban areas or small regions of a country. Registration of cases may also be voluntary rather than mandatory. In developing countries, many cases of cancer may not be diagnosed accurately or at all. For these reasons, data for these populations may be less accurate than for the Canadian population. The population-based system of cancer registries in Canada allows for long-term surveillance of patterns and trends, which can identify issues that are important for health care planning, identification of emerging trends and improvement of surveillance, as well as for monitoring the population impact of measures to control cancer.

\section{Implications and conclusions}

Research suggests that at least half of all new cancer cases and cancer deaths worldwide are preventable. ${ }^{15,16}$ In devel- oped countries, the largest attributable fractions for modifiable risk factors are tobacco smoking (30\%) and poor diet, obesity and physical inactivity combined (30\%). ${ }^{16}$ Although cancer mortality rates have declined in Canada in the past 2 decades, incidence rates declined little during this period. This differential trend in mortality and incidence places more emphasis on the need for increased public awareness of risk factors, as well as the development of policies and facilities that target modifiable risk factors (e.g., tobacco use, physical activity, nutrition, chronic infections). In addition, there is a need for more investment into etiologic research and better data on cancer staging in order to understand and address differences in survival among patients with cancer. More research is also needed to delineate cross-country disparities in cancer burden, as well as on the prevention of existing and emerging cancers.

In the clinical setting, primary care physicians can place a greater focus on prevention and risk assessment (Box 1). For example, it is becoming increasingly important to be vigilant about cancer in women, especially among those aged 20-59 years, as the incidence of breast, cervical, lung and thyroid cancers and melanoma continues to drive cancer rates in this

Table 4: Age-standardized incidence and mortality rates for all cancers * by region in $2002 \dagger^{11}$

\begin{tabular}{|c|c|c|c|c|}
\hline Sex, region & No. of new cases & $\begin{array}{l}\text { Age-standardized } \neq \\
\text { incidence rate, } \\
\text { per } 100000\end{array}$ & No. of deaths & $\begin{array}{c}\text { Age-standardized } \neq \\
\text { mortality rate, } \\
\text { per } 100000\end{array}$ \\
\hline World & 5801839 & 209.6 & 3795991 & 137.7 \\
\hline More developed countries§ & 2698175 & 314.1 & 1503060 & 169.6 \\
\hline Australia and New Zealand & 56119 & 349.7 & 24812 & 149.1 \\
\hline Canada & 71785 & 327.3 & 35450 & 156.6 \\
\hline Western Europe & 472102 & 326.4 & 264672 & 173.9 \\
\hline Southern Europe & 348688 & 299.4 & 208141 & 170.1 \\
\hline World & 5060657 & 161.5 & 2927896 & 92.1 \\
\hline More developed countries§ & 2317939 & 228.0 & 1185412 & 102.5 \\
\hline Less developed countries & 2735386 & 128.8 & 1737796 & 83.1 \\
\hline United States & 669941 & 308.7 & 270105 & 111.9 \\
\hline Australia and New Zealand & 47606 & 280.3 & 19611 & 103.4 \\
\hline Canada & 65726 & 272.4 & 30514 & 114.3 \\
\hline Western Europe & 401570 & 244.6 & 210402 & 106.1 \\
\hline Southern Europe & 268601 & 208.1 & 140255 & 92.2 \\
\hline United Kingdom & 138275 & 260.6 & 74953 & 122.7 \\
\hline
\end{tabular}

*Excluding non-melanoma skin cancers.

tEstimates are for the middle of 2002 using the most recent available data.

$\ddagger$ Age-standardized to the World Standard Population. ${ }^{12}$

§Includes North America, Japan, Europe, Australia and New Zealand. ${ }^{11}$

ๆIncludes Africa, Asia, Central and South America, Caribbean, Melanesia, Micronesia and Polynesia." 
Box 1. Implications and recommendations for primary care physicians and health care providers

- Although the risk of cancer is low, it is increasing among young adults. Clinicians should consider cancer in the differential diagnosis for young patients, especially young women.

- $\quad$ Given the rising rates of thyroid cancer in men and women, as well as liver cancer in men, clinicians should be vigilant for these cancers.

- $\quad$ Although individual risk of developing cancer is not increasing and the risk of dying is declining, clinicians should promote healthy lifestyles and recommend cancer screening programs.

- Because nearly 3\% of Canadians have received a diagnosis of cancer in the last 15 years, clinicians need to be aware of late treatment effects, second and recurrent cancers, and issues related to surviving cancer.

group. Early detection of cancer through regular screening, along with effective treatment, can help reduce the severity of disease and mortality from cancers such as colorectal, cervical, prostate and breast.

Other continuing challenges in the control of cancer include the need to improve data quality, timeliness of reporting, and the scope of cancer surveillance, as well as improved dissemination of surveillance information. These improvements will result in a wider availability of information to policy-makers, health care professionals and health care managers for the development of strategies for prevention, screening, treatment and supportive care.

Perhaps most importantly, the current data on major and emerging cancers emphasize the need for the development and effective implementation of cancer control activities, programs, and policies at all levels - individual, health care provider, health care system and government - to slow the rise in cancer burden caused by Canada's population growth and changing demographic profile.

This article has been peer reviewed.

\section{Competing interests: None declared.}

Acknowledgements: We thank Lin Xie for statistical support, Dr. Eva Grunfeld for reviewing the article, and Monika Dixon for coordination of the writing and manuscript submission.

Canadian Cancer Statistics is produced by a long-standing partnership of the Canadian Cancer Society, National Cancer Institute of Canada, Public Health Agency of Canada, Statistics Canada, Canadian Council of Cancer Registries, Canadian Association of Provincial Cancer Agencies, as well as university and provincial and territorial cancer agency-based researchers.

The steering committee for Canadian Cancer Statistics is a committee of the Canadian Cancer Society and the National Cancer Institute of Canada and is responsible for the annual production of Canadian Cancer Statistics, which is available at www.cancer.ca/statistics.

The Canadian Cancer Registry is based on a strong partnership among the provincial and territorial cancer registries, which regularly provide Statistics Canada with data, which are processed and standardized. A copy of the data is provided to The Public Health Agency of Canada, which conducts most of the analyses appearing in Canadian Cancer Statistics. Provincial and territorial cancer registries are responsible for the collection and quality assurance of most of the data included in this report.

\section{REFERENCES}

1. Garcia M, Jemal A, Ward EM, et al. Global cancer facts \& figures 2007. Atlanta (GA): American Cancer Society; 2007

2. Canadian Cancer Society and the National Cancer Institute of Canada. Canadian cancer statistics 2008. Toronto (ON): 2008. Available: www.cancer.ca/Canada-wide /About\%20cancer/Cancer\%20statistics/Canadian\%20Cancer\%20Statistics.aspx?sc_1 ang=en (accessed 2008 Oct 15).

3. National Cancer Institute of Canada. Evaluation of cancer estimates: 1987-1991, Canadian Cancer Statistics 1996. Toronto (ON): 1996.

4. Brisson J, Major D, Pelletier E. Évaluation de l'exhaustivité du fichier des tumeurs du Québec. Québec (QC): Institut national de la santé publique; 2003.

5. Wiljer D, Le L, Logan H, et al. From policy to practice: assessing the impact of staging policies for recording cancer stage across Canada. Healthc $Q 2008 ; 11: 98-103$

6. Gilmore, J. Report on smoking in Canada, 1985 to 2001. Ottawa (ON); Statistics Canada; 2002. Available: www.statcan.ca/english/research/82F0077XIE /82F0077XIE2001001.pdf (accessed 2008 Oct 15).

7. Health Canada. Progress report on cancer control in Canada. Ottawa (ON): Health Canada; 2004

8. Kent WD, Hall SF, Isotalo PA, et al. Increased incidence of differentiated thyroid carcinoma and detection of subclinical disease. CMAJ 2007;177:1357-61.

9. McGlynn KA, Tsao L, Hsing AW, et al. International trends and patterns of primary liver cancer. Int J Cancer 2001;94:290-6.

10. Bosch FX, Ribes J, Diaz M et al. Primary liver cancer: worldwide incidence and trends. Gastroenterology 2004;127(5 Suppl 1):S5-S16.

11. Ferlay J, Bray F, Pisani P, et al. GLOBOCAN 2002: cancer incidence, mortality and prevalence worldwide. IARC cancer base no 5 (version 2.0). Lyon (France): The International Agency for Research on Cancer (IARC) Press; 2004.

12. Curado MP, Edwards B, Shin HR, et al. Cancer incidence in five continents. Lyon (France): The International Agency for Research on Cancer Scientific Publications; 2007.

13. Espey DK, Wu XC, Swan J, et al. Annual report to the nation on the status of cancer, 1975-2004, featuring cancer in American Indians and Alaska Natives. Cancer 2007; 110:2119-52

14. Mackay J, Jemal A, Lee NC, et al. The cancer atlas. Atlanta (GA): American Cancer Society; 2006

15. Harvard Report on Cancer Prevention. Volume 1: Causes of human cancer. Cancer Causes Control 1996;7(Suppl 1):S3-59.

16. Adami HO, Day NE, Trichopoulos D, et al. Primary and secondary prevention in the reduction of cancer morbidity and mortality. Eur J Cancer 2001;37(Suppl 8):S118-27.

Correspondence to: Dr. Loraine D. Marrett, Population Studies and Surveillance, Cancer Care Ontario, 620 University Ave., Toronto ON M5G 2L7; fax416 971-6888; stats@cancer.ca

Steering Committee members: Larry Ellison MSc (Health Statistics Division, Statistics Canada), Robert Semenciw MSc (Health Promotion and Chronic Disease Prevention, Public Health Agency of Canada), Howard Morrison PhD (Health Promotion and Chronic Disease Prevention, Public Health Agency of Canada), Les Mery MSc (Surveillance Action Group, Canadian Partnership Against Cancer), Heather Logan BScN MHSc (Cancer Control Policy, Canadian Cancer Society and National Cancer Institute of Canada), Brent Schacter MD (Canadian Association of Provincial Cancer Agencies and CancerCare Manitoba, Canada). 